\title{
An Improved Approach for Solving Partial Differential Equation Based on Reproducing Kernel Method
}

\author{
Mingjing Du \\ Institute of Computer Information Management, Inner Mongolia University of Finance and Economics, Hohhot 010070, China \\ Correspondence should be addressed to Mingjing Du; 724297269@qq.com
}

Received 8 October 2021; Accepted 11 November 2021; Published 30 November 2021

Academic Editor: Joni Zhong

Copyright ( $\odot 2021$ Mingjing Du. This is an open access article distributed under the Creative Commons Attribution License, which permits unrestricted use, distribution, and reproduction in any medium, provided the original work is properly cited.

The traditional reproducing kernel method (TRKM) cannot obtain satisfactory numerical results for solving the partial differential equation (PDE). In this study, for the first time, the abovementioned problems are solved by adaptive piecewise interpolation reproducing kernel method (APIRKM) to obtain the exact and approximate solutions of partial differential equations by means of series expansion using reconstructed kernel function. The highlight of this paper is to obtain more accurate approximate solution and save more time through adaptive discovery. Numerical solutions of the three examples show that the present method is more advantageous than TRKM.

\section{Introduction}

The numerical methods of PDE play an important role in many applications, which have been frequently applied in many areas such as communication engineering, fluid dynamics, economics, quantum mechanics, fluid mechanics, chemical reactions, physics, and electrical networks [1]. Many researchers have utilized various numerical methods to solve PDE [2-9]. In [2-9], Allan used the optimal auxiliary function method to solve PDEs, which was extended to general PDEs [2]. Jornet used the differential transform method for solving Burgers' PDE [3]. Radek solved PDEs using the lattice Boltzmann method [4]. Wang employed localized Chebyshev collocation method for solving elliptic PDEs in arbitrary 2D domains [5]. Young adopted the two-step MPS-MFS ghost point method for solving PDEs [6]. Han used a derivativefree method for solving elliptic PDEs with deep neural networks [7]. Ren used a higher order nonlocal operator method for solving PDEs [8]. Stephen solved the conservation equation by using the symmetric multiple reduction method [9]. In the previous works $[10,11]$, the author presented the TRKM for solving all kinds of PDEs. Nevertheless, the TRKM cannot get accurate numerical solutions. The TRKM must be improved. The main purpose of this paper is to find an effective and time-saving computational method through adaptive technology. In order to present the APIRKM, we mainly consider the PDE arising from communication engineering as follows:

$$
\left\{\begin{array}{l}
\frac{\partial u(x, t)}{\partial t}+\alpha(x, t) \frac{\partial^{2} u(x, t)}{\partial x^{2}}+\beta(x, t) \frac{\partial u(x, t)}{\partial x}+\gamma(x, t) u(x, t)=f(x, t),(x, t) \in \Omega \\
u(x, 0)=u_{0}(x), x \in \Omega_{x}, u(0, t)=u(1, t)=0, t \in[0, T]
\end{array}\right.
$$


where $0<\epsilon \leq 1$ and $0<\mu \leq 1$ are two small parameters; $\alpha(x, t), \quad \beta(x, t), \quad \gamma(x, t)$, and $f(x, t)$ are given, $\Omega=\Omega_{x} \times(0, T], \Omega_{x}=(0,1)$.

\section{Reproducing Kernel Space (RKS)}

The RKSs and their reproducing kernels used in this paper are given as follows:
(1) The RKS $W_{2}^{1}[0,1]=\{u \mid u\}$ is one-variable absolutely continuous function, $\left.u^{\prime} \in L^{2}[0,1]\right\}$.

An inner product is

$$
\langle u(s), v(s)\rangle_{W_{2}^{1}}=u(0) v(0)+\int_{0}^{1} u^{\prime}(s) \cdot v^{\prime}(s) d s, u(s), v(s) \in W_{2}^{1}[0,1] .
$$

The reproducing kernel is

$$
R_{s}^{\{1\}}(t)=\left\{\begin{array}{l}
1+s, t>s \\
1+t, s>t
\end{array}\right. \text {. }
$$

(2) The RKS $W_{2}^{2}[0,1]=\left\{u \mid u, u^{\prime}\right.$ are one-variable absolutely continuous functions, $\left.u(0)=0, u^{\prime \prime} \in L^{2}[0,1]\right\}$. An inner product is

$$
\langle u(s), v(s)\rangle_{W_{2}^{2}}=\sum_{i=0}^{1} u^{(i)}(0) v^{(i)}(0)+\int_{0}^{1} u^{\prime \prime}(s) \cdot v^{\prime \prime}(s) d s, u(s), v(s) \in W_{2}^{2}[0,1] .
$$

The reproducing kernel is

$$
R_{s}^{\{2\}}(t)=\left\{\begin{array}{l}
-s\left(s^{2}-6 t-3 s t\right) / 6, t>s \\
-t^{3} / 6+s t(2+t) / 2, s>t
\end{array} .\right.
$$

(3) The RKS $W_{2}^{3}[0,1]=\left\{u \mid u, u^{\prime}, u^{\prime \prime}\right.$ are one-variable absolutely continuous functions, $u(0)=u(1)=$ $\left.0, u^{\prime \prime \prime} \in L^{2}[0,1]\right\}$.

An inner product:

$$
\langle u(s), v(s)\rangle_{W_{2}^{3}}=\sum_{i=0}^{2} u^{(i)}(0) v^{(i)}(0)+\int_{0}^{1} u^{\prime \prime \prime}(s) \cdot v^{\prime \prime \prime}(s) d s, u(s), v(s) \in W_{2}^{3}[0,1] .
$$

The reproducing kernel:

$$
R_{s}^{\{3\}}(t)=\left\{\begin{array}{l}
R(s, t), t>s \\
R(t, s), s>t
\end{array}\right.
$$

where $R(t, s)$ and $R(s, t)$ are given in [10].

\section{Representation of the Solution}

Before using the TRKM to solve equation (1), it is necessary to homogenize the initial and boundary conditions. Then, we get a new equation and denote the exact solution of the new equation by $U(x, t), D=(x, t) \in[0,1] \times[0,1]$, and we get

$$
\left\{\begin{array}{l}
L U(x, t)=F(x, t) \\
U(x, 0)=U(0, t)=U(1, t)=0
\end{array} .\right.
$$

The reproducing kernel space $W_{2}^{1}[0,1], W_{2}^{2}[0,1]$, $W_{2}^{3}[0,1], \quad H(D)=W_{2}^{3}[0,1] \otimes W_{2}^{2}[0,1], H_{1}(D)=W_{2}^{1}[0,1]$ $\otimes W_{2}^{1}[0,1]$, and $\zeta_{j}(x, t)$ have been defined in [11], the exact solution of equation (8) is $U(x, t)=\sum_{j=1}^{\infty} F\left(x_{j}, t_{j}\right) \zeta_{j}(x, t)$, and the approximate solution is $U_{n}(x, t)=\sum_{j=1}^{n} F\left(x_{j}, t_{j}\right)$ $\zeta_{j}(x, t)$. The error estimate and convergence analysis are given in $[12,13]$, which will not be elaborated in this paper. However, satisfactory results cannot be obtained by directly using the above method, so the adaptive piecewise interpolation is used. The main idea is as follows:

Firstly, the region $(x, t) \in D$ is divided into $n$ small regions, $\quad\left[x_{0}, x_{1}\right] \times[0,1], \quad\left[x_{1}, x_{2}\right] \times[0,1], \quad \ldots$, $\left[x_{n-1}, x_{n}\right] \times[0,1]$, and then the numerical solution of the first small region $\left[x_{0}, x_{1}\right] \times[0,1]$ is solved by using the TRKM, so the boundary value of the first small region is the initial value condition of the second small region $\left[x_{1}, x_{2}\right] \times[0,1]$; by parity of reasoning, the boundary value of the last small region is given.

Secondly, a maximum absolute error $\delta$ is set in each region $\left[x_{k-1}, x_{k}\right] \times[0,1], k=0, \ldots, n$; when the absolute errors are greater than $\delta$, the region will continue to divide until the absolute errors are smaller than $\delta$.

Finally, when the absolute errors are smaller than $\delta$, the dividing is stopped, and the optimal small region is obtained, and then the TRKM is used to solve the problem in each 
region $\left[x_{k-1}, x_{k}\right]$ to obtain the numerical solution of the whole region $[0,1] \times[0,1]$.

\section{Numerical Examples}

Example 1. Considering the following PDE

$$
\frac{\partial u(x, t)}{\partial t}-\frac{\partial^{2} u(x, t)}{\partial x^{2}}+\frac{\partial u(x, t)}{\partial x}-u(x, t)=f(x, t),
$$

with the initial condition and boundary condition,

$$
\begin{aligned}
u(x, 0) & =\sin [8 \pi x(x-1)], u(0, t) \\
& =\sin [8 \pi t(t-1)], u(1, t)=\sin [8 \pi t(t-1)] .
\end{aligned}
$$

The exact solution of equation (9) is $u(x, t)=\sin \left[2 \pi(2 x-1)^{2}+2 \pi(2 t-1)^{2}\right] ; f(x)$ is obtained by $u(x, t)$. By Mathematica 7.0 , let $N=10$ and $t=1$. Figure 1 shows the exact solution. Figure 2 shows the numerical solutions by the TRKM (red line). Figure 3 shows the numerical solutions by the APIRKM (red line) for $n=10^{-3}$ and $\delta=1$. Figure 4 shows the numerical solutions by the APIRKM (red line) for $n=10^{-12}$ and $\delta=10^{-9}$; the blue line in Figures $2-4$ is the exact solution. Figure 5 provides the absolute errors by the TRKM. Figure 6 provides the absolute errors by the APIRKM for $n=10^{-3}$ and $\delta=1$. Figure 7 provides the absolute errors by the APIRKM for $n=10^{-12}$ and $\delta=10^{-9}$.

Example 2. Considering the following PDE

$$
\frac{\partial u(x, t)}{\partial t}-\frac{1}{2} \frac{\partial^{2} u(x, t)}{\partial x^{2}}+\frac{\partial u(x, t)}{\partial x}+u(x, t)=f(x, t),
$$

with the initial condition and boundary condition,

$$
u(x, 0)=0, u(0, t)=t, u(1, t)=-t .
$$

The exact solution of equation (11) is $u(x, t)=t \cdot \cos [\pi x] ; f(x)$ is given by $u(x, t)$. By Mathematica 7.0, let $N=10$ and $t=0.5$. Figure 8 shows the absolute errors by the TRKM. Figure 9 provides the absolute errors by the APIRKM for $n=10^{-2}$ and $\delta=10^{-5}$. Figure 10 provides the absolute errors by the APIRKM for $n=10^{-9}$ and $\delta=10^{-12}$.

Example 3. Considering the following Black-Scholes equation in financial economics

$$
\frac{\partial V(S, t)}{\partial t}+\frac{1}{2} \sigma^{2} S^{2} \frac{\partial^{2} V(S, t)}{\partial S^{2}}+(r-q) S \frac{\partial V(S, t)}{\partial S}-r V(S, t)=0
$$

with the initial and boundary conditions, $V(S, 0)=\mathrm{Se}^{-q T}-\mathrm{Ee}^{-r T}, \quad V(0, t)=-\mathrm{Ee}^{-r(T-t)}, \quad V(1, t)$ $=e^{-q(T-t)}-\mathrm{Ee}^{-r(T-t)}$, in which $r$ is the risk-free rate, $q$ is the red rate, $T$ is the maturity date, $\sigma$ is the volatility, $E$ is the strike price, and the exact solution is $V(S, t)=\mathrm{Se}^{-q(T-t)}-\mathrm{Ee}^{-r(T-t)}$. Let $E=2, r=0.05, q=0.2$, and $\sigma=0.3$. By Mathematica 7.0, $N=10$ and $n=10^{-9}$.

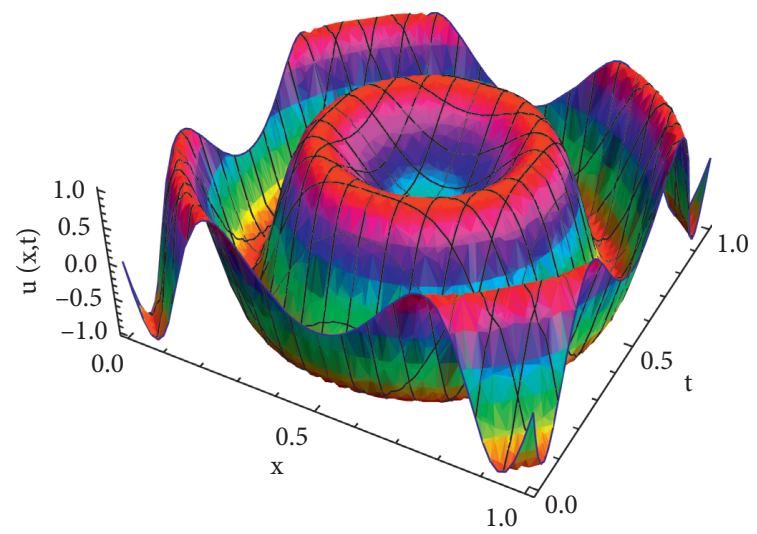

Figure 1: Exact solutions of Example 1.

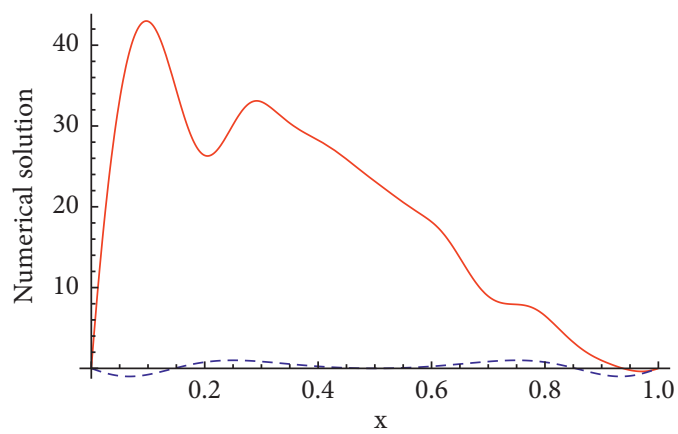

Figure 2: Numerical solutions of Example 1 by the TRKM for $t=1$.

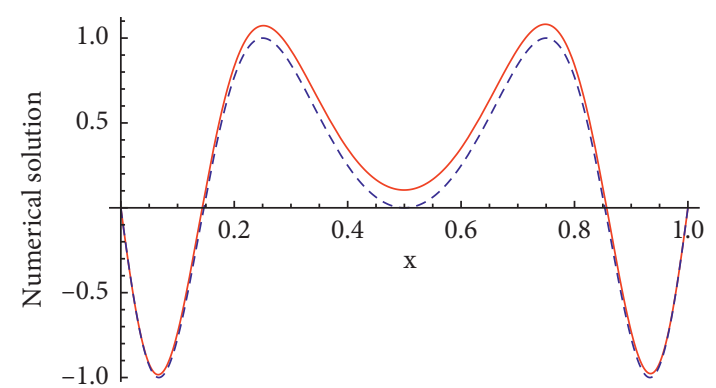

FIgURE 3: Numerical solutions of Example 1 by the APIRKM for $t=1, n=10^{-3}$, and $\delta=1$.

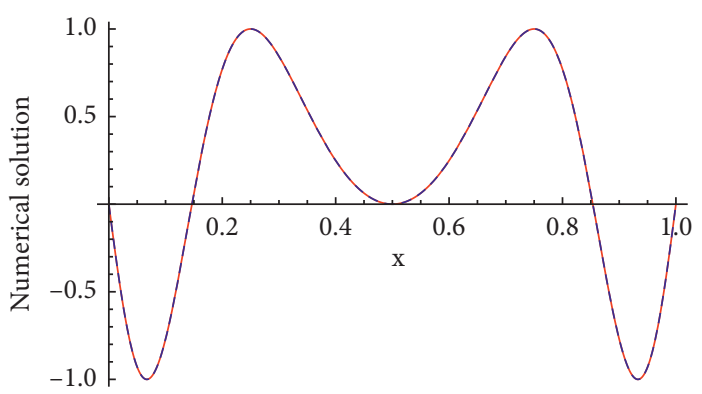

FIgURE 4: Numerical solutions of Example 1 by the APIRKM for $t=1, n=10^{-12}$, and $\delta=10^{-9}$. 


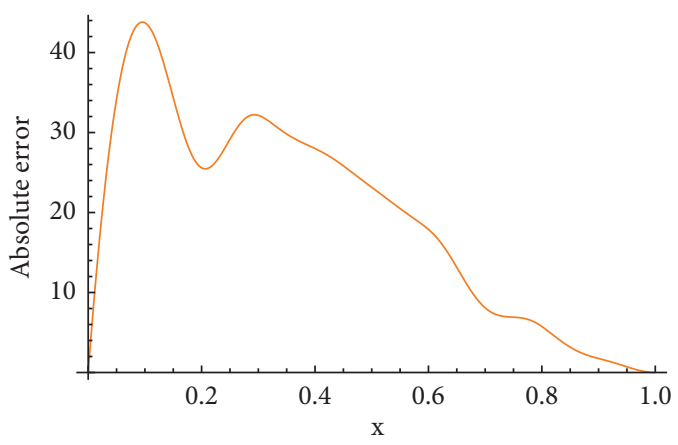

FIgUre 5: Absolute errors of Example 1 by the TRKM for $t=1$.

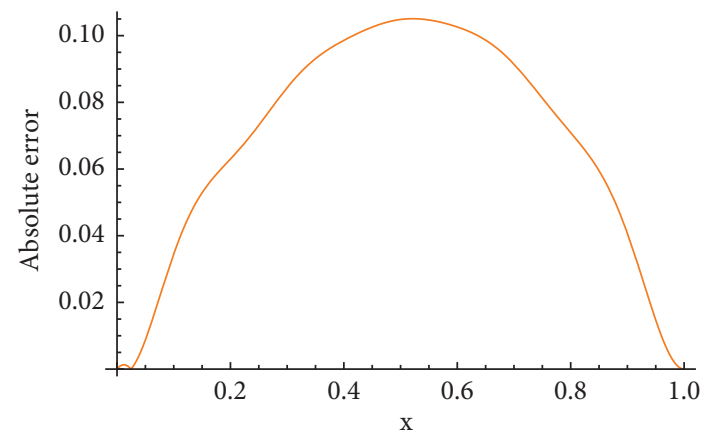

Figure 6: Absolute errors of Example 1 by the APIRKM for $t=1$, $n=10^{-3}$, and $\delta=1$.

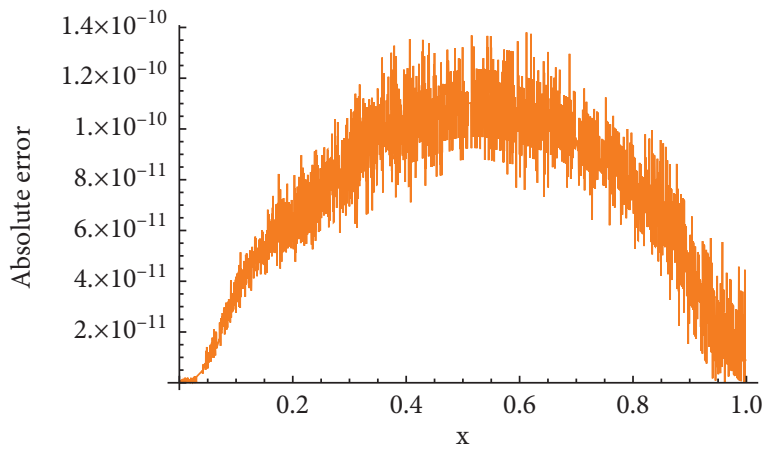

FIgUre 7: Absolute errors of Example 1 by the APIRKM for $t=1$, $n=10^{-12}$, and $\delta=10^{-9}$.

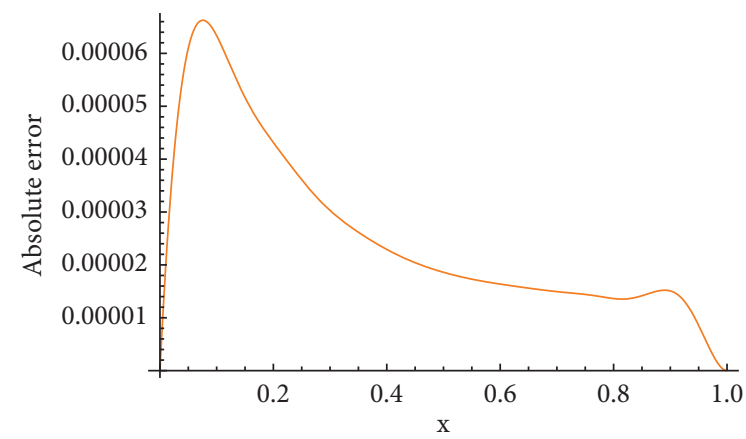

FIgURE 8: Absolute errors of Example 2 by the TRKM for $t=0.5$.

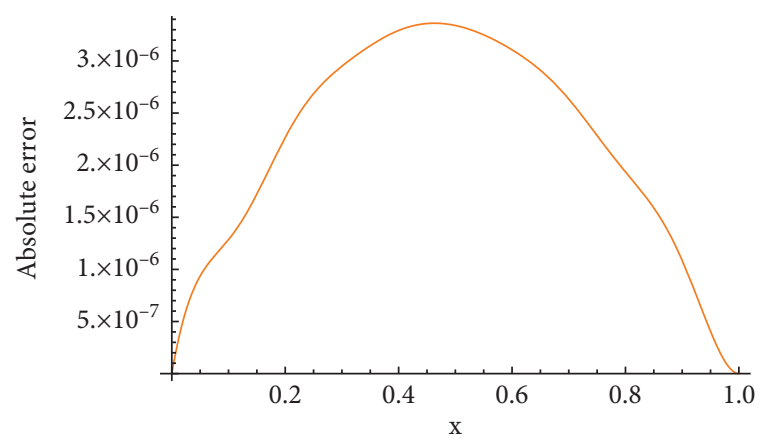

FIgURE 9: Absolute errors of Example 2 by the APIRKM for $t=0.5$, $n=10^{-2}$, and $\delta=10^{-5}$.

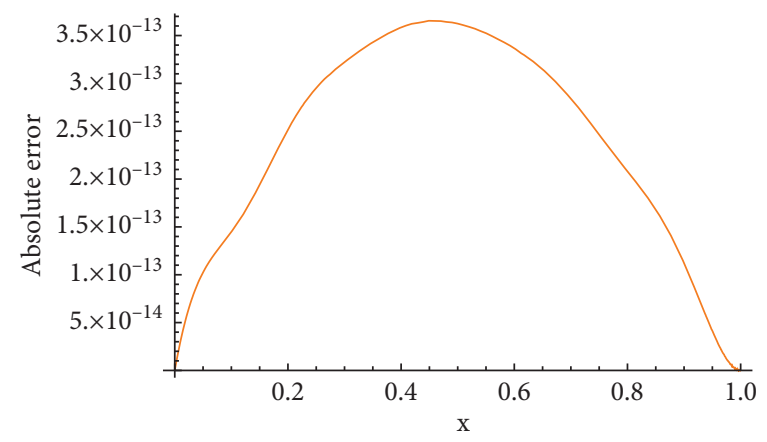

FIgURE 10: Absolute errors of Example 2 by the APIRKM for $t=0.5, n=10^{-9}$, and $\delta=10^{-12}$.

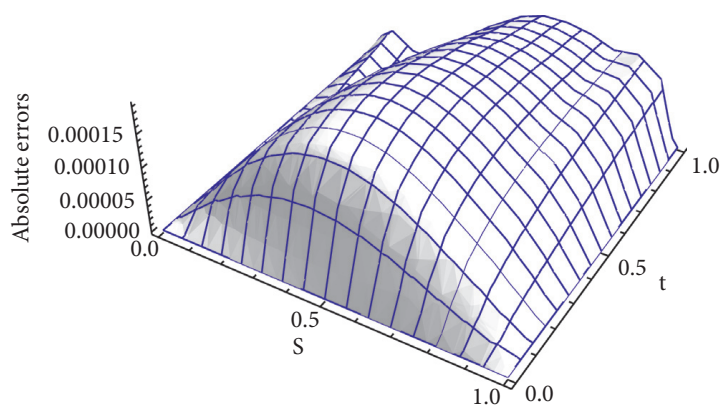

FIGURE 11: Absolute errors of Example 3 by the TRKM.

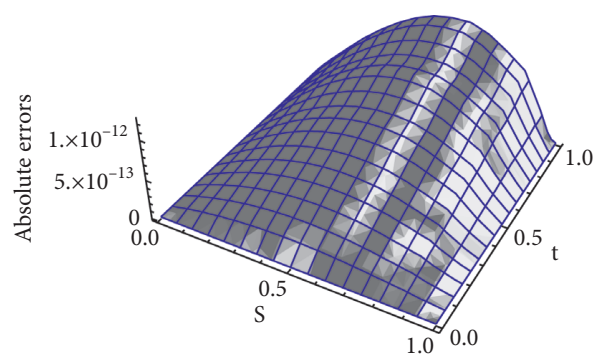

FIgURE 12: Absolute errors of Example 3 by the APIRKM. 
Figure 11 shows the absolute errors by TRKM. Figure 12 shows the absolute errors by APIRKM.

\section{Conclusions}

In this paper, the APIRKM is used to successfully solve a glass of PDE, which is widely used in solving science and engineering problems. The three numerical examples show that the more the piece regions we devide, the more accurate the results we get. Moreover, the APIRKM presented in this paper can solve more complex PDEs.

\section{Data Availability}

The data used to support the findings of this study are available from the corresponding author upon request.

\section{Conflicts of Interest}

The authors declare that they have no conflicts of interest.

\section{Acknowledgments}

This work was supported by the Natural Science Foundation of Inner Mongolia (No. 2019BS01011), the Science Research Project of Higher Education in Inner Mongolia Autonomous Region (No. NJZY20158), and the Program for Young Talents of Science and Technology in Universities of Inner Mongolia Autonomous Region (No. NJYT-20-B18).

\section{References}

[1] A. S. Nielsen, G. Brunner, and J. S. Hesthaven, "Communication-aware adaptive Parareal with application to a nonlinear hyperbolic system of partial differential equations," Journal of Computational Physics, vol. 371, pp. 483-505, 2018.

[2] L. Zada, R. Nawaz, K. S. Nisar et al., "New approximateanalytical solutions to partial differential equations via auxiliary function method," Partial Differential Equations in Applied Mathematics, vol. 4, Article ID 100045, 2021.

[3] M. Jornet, "Uncertainty quantification for the random viscous Burgers' partial differential equation by using the differential transform method," Nonlinear Analysis, vol. 209, Article ID 112340, 2021.

[4] F. Radek and S. Robert, "Equivalent finite difference and partial differential equations for the lattice Boltzmann method," Computers \& Mathematics with Applications, vol. 90, pp. 96-103, 2021.

[5] F. Wang, Q. Zhao, Z. Chen, and C.-M. Fan, "Localized Chebyshev collocation method for solving elliptic partial differential equations in arbitrary 2D domains," Applied Mathematics and Computation, vol. 397, Article ID 125903, 2021.

[6] D. L. Young, S.-R. Lin, C.-S. Chen, and C. S. Chen, "Two-step MPS-MFS ghost point method for solving partial differential equations," Computers \& Mathematics with Applications, vol. 94, pp. 38-46, 2021.

[7] J. Han, M. Nica, and A. R. Stinchcombe, "A derivative-free method for solving elliptic partial differential equations with deep neural networks," Journal of Computational Physics, vol. 419, Article ID 109672, 2020.

[8] H. Ren, X. Zhuang, and T. Rabczuk, "A higher order nonlocal operator method for solving partial differential equations,"
Computer Methods in Applied Mechanics and Engineering, vol. 367, Article ID 113132, 2020.

[9] S. C. Anco and M. L. Gandarias, "Symmetry multi-reduction method for partial differential equations with conservation laws," Communications in Nonlinear Science and Numerical Simulation, vol. 91, Article ID 105349, 2020.

[10] M. J. Du, Y. L. Wang, and C. L. Tumer, "Reproducing kernel method for singularly perturbed 2D elliptic partial differential equations," Journal of Computational Analysis and Applications, vol. 3, pp. 32-37, 2015.

[11] Y. Wang, L. Su, X. Cao, and X. Li, "Using reproducing kernel for solving a class of singularly perturbed problems," Computers \& Mathematics with Applications, vol. 61, no. 2, pp. 421-430, 2011.

[12] M.-J. Du, Y.-L. Wang, C.-L. Temuer, and D. Tian, "A modified reproducing kernel method for solving Burgers' equation arising from diffusive waves in fluid dynamics," Applied Mathematics and Computation, vol. 315, pp. 500-506, 2017.

[13] M. Du, X. Qiao, B. Wang, Y. Wang, and B. Gao, "A novel method for numerical simulation of sand motion model in beach formation based on fractional Taylor-Jumarie series expansion and piecewise interpolation technique," Applied Mathematics and Computation, vol. 347, pp. 15-21, 2019. 